\title{
Synthesis of HCV Protease Inhibitor MK-6325
}
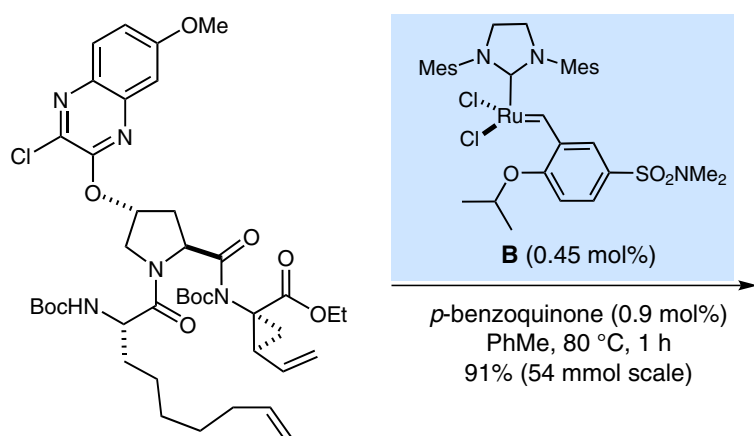

$\mathrm{mp}$ not reported

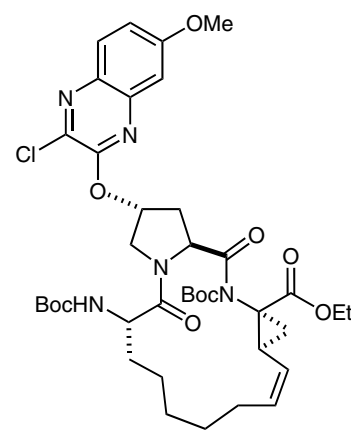

C

$\mathrm{mp}$ not reported
Gategory

Synthesis of Natural

Products and

Potential Drugs

\section{Key words}

\section{MK-6325}

HCV NS3/4A

protease inhibitors

ring-closing

metathesis

Suzuki-Miyaura coupling

macrocyclization

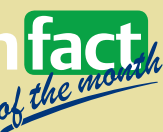

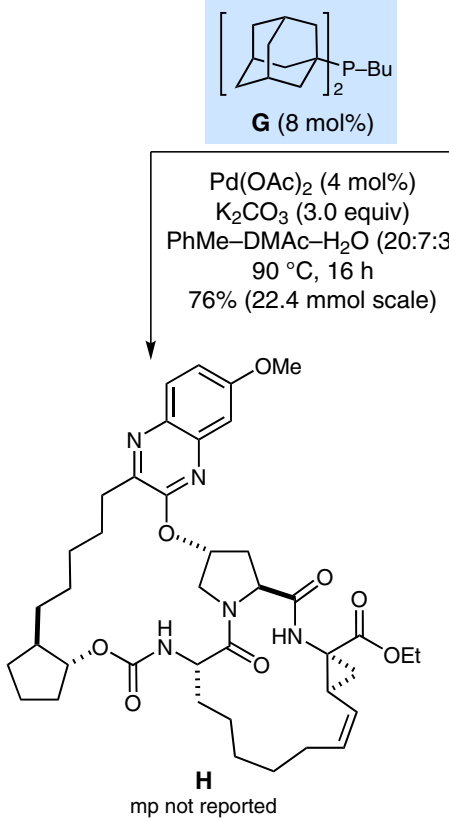
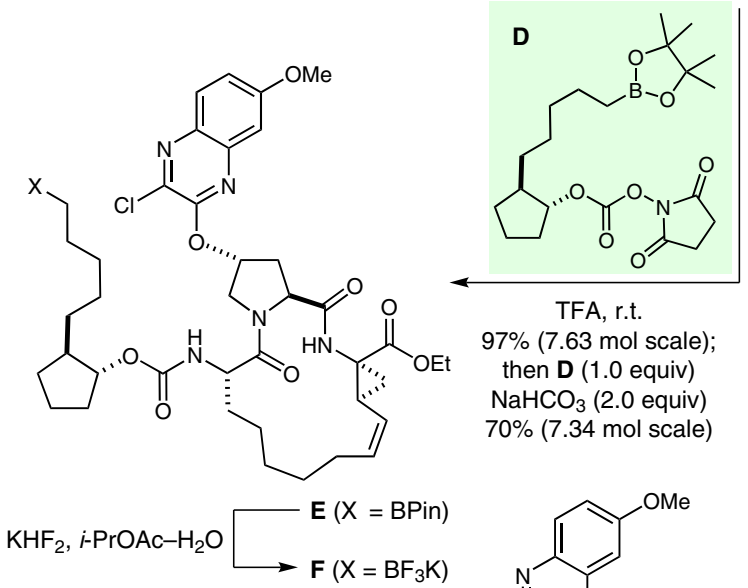

TFA, r.t.

$97 \%$ (7.63 mol scale);

then $\mathbf{D}$ (1.0 equiv)

$\mathrm{NaHCO}_{3}$ (2.0 equiv)

$70 \%$ (7.34 mol scale)

$\mathrm{mp}$ not reported

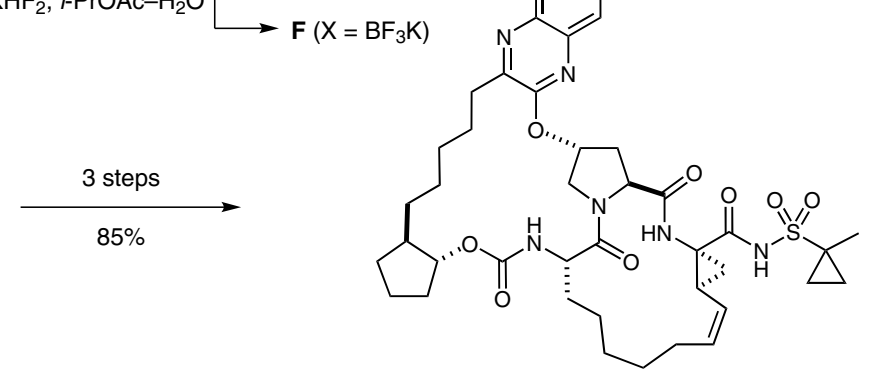

Significance: MK-6325 is a potent HCV NS3/4A protease inhibitor. The construction of the daunting bis-macrocyclic structure was accomplished by a ring-closing metathesis ( $\mathrm{RCM}$ ) to forge the 15-membered macrocycle followed by an intramolecular Suzuki-Miyaura cross-coupling to append the 18-membered macrocycle.

sYNFACTS Contributors: Philip Kocienski

Synfacts 2015, 11(6), 0571 Published online: 18.05.2015

Dol: 10.1055/s-0034-1380762; Reg-No.: K02715SF
Comment: The route depicted delivered multikilogram quantities of the MK-6325. Construction of fragment $\mathbf{D}$ was achieved using (1) a Novozyme 435 resolution with succinic anhydride and (2) an iridium-catalyzed hydroboration. CataCXium A (G) was superior to all other ligands evaluated for the Suzuki-Miyaura reaction. 